\title{
Studying and modelling the combined effect of temperature and water activity on the growth rate of $P$. expansum
}

\author{
R. Lahlali ${ }^{\mathrm{a}}$, M.N. Serrhini ${ }^{\mathrm{b}}$, M.H. Jijaklia,* \\ ${ }^{a}$ Unité de Phytopathologie, Faculté Universitaire des Sciences Agronomiques de Gembloux, Passage des Déportés 2, 5030 Gembloux, Belgium \\ ${ }^{\mathrm{b}}$ Département de Phytopathologie, Ecole Nationale d'Agriculture de Meknès, B P S/40, 50000 Meknès, Morocco
}

Received 18 August 2004; received in revised form 7 February 2005; accepted 17 February 2005

\begin{abstract}
The effect of solutes, water activity $\left(a_{\mathrm{w}}, 0.890-0.980\right)$ and temperature $\left(5-25^{\circ} \mathrm{C}\right)$ on the mycelial growth rate of Penicillium expansum was evaluated. The growth rate dropped as the temperature and $a_{\mathrm{w}}$ of the medium decreased. $\mathrm{NaCl}$ was the solute causing the greatest growth rate reduction, followed by glucose, glycerol and sorbitol. Statistical analysis of the results showed a significant effect of solute, $a_{\mathrm{w}}$, temperature and combinations of two or three of these factors $(P<0.0001)$. Whatever the solutes and $a_{\mathrm{w}}$ values, the initiation of colony growth required an additional day at $15{ }^{\circ} \mathrm{C}$ and $5{ }^{\circ} \mathrm{C}$ as compared to initiation at $25{ }^{\circ} \mathrm{C}$. Growth models based on the results obtained with sorbitol and glycerol differed only slightly, with $R^{2}$ values of $97.00 \%$ and $97.95 \%$, respectively. The response surfaces of both quadratic polynomial models showed that $P$. expansum should be able to grow at low $a_{\mathrm{w}}(0.890)$ and that growth at $25{ }^{\circ} \mathrm{C}$ should be fastest at $a_{\mathrm{w}}$ values ranging from 0.960 to 0.980 . Both models presented a good fit between predicted and observed values.
\end{abstract}

(c) 2005 Elsevier B.V. All rights reserved.

Keywords: Solute; Temperature; Growth rate; Penicillium expansum; Water activity; Quadratic polynomial models

\section{Introduction}

Penicillium expansum, responsible for blue mould, causes severe decay of apples and pears during refrigerated storage. Infection of fresh tissue occurs through wounds on fruits but also through some natural openings such as lenticels (Bondoux, 1992; Rosenberger, 1990). P. expansum can attack fruit on trees but also during and after harvest, during transit

\footnotetext{
* Corresponding author. Tel.: +32 81622431; fax: +32 81610126 .

E-mail address: jijakli.h@fsagx.ac.be (M.H. Jijakli).
}

and storage in packinghouses. At these stages, apples and pears may undergo various environmental conditions that favour the development of this pathogen. Water availability (water activity, $a_{\mathrm{w}}$ ) and temperature are the major abiotic parameters determining the potential for germination and growth of propagules on the fruit surface (Magan and Lacey, 1988; Plaza et al., 2003). The optimal $a_{\mathrm{w}}$ for most decays caused by fungi ranges from 0.96 to 0.98 , although some fungi can grow at a lower $a_{\mathrm{w}}$ (Gervais et al., 1988a,b).

Studies of how the $a_{\mathrm{w}}$ affects the growth rate of Penicillium species show that $P$. digitatum is unable 
to grow at an $a_{\mathrm{w}}$ lower than 0.90 (Lacey, 1989). A more recent 'in vitro' study has shown that at low temperature, germination and growth of three major postharvest citrus pathogens ( $P$. digitatum, $P$. italicum and Geotrichum candidum) are markedly influenced by environmental conditions such as temperature and water activity (Plaza et al., 2003). P. italicum was found to germinate and grow faster than $P$. digitatum and $G$. candidum, particularly at $0.95 a_{\mathrm{w}}$. In addition, $P$. italicum was able to germinate and grow under the driest conditions studied $\left(a_{\mathrm{w}}=0.87\right)$, while $G$. candidum failed to germinate below $a_{\mathrm{w}}=0.95$. For $P$. italicum and $P$. digitatum, the highest growth rates were observed 'in vitro' at temperatures ranging from $10{ }^{\circ} \mathrm{C}$ to $25{ }^{\circ} \mathrm{C}$. Growth generally stops beyond 30 ${ }^{\circ} \mathrm{C}$ (Loussert, 1985). How water activity and temperature affect the growth rate of $P$. expansum has not been studied.

Many mathematical models contribute to predicting the influence of both of these factors and their interactions on the growth of microorganisms that degrade processed food (McMeekin et al., 1993, 2002), but predictive modelling of filamentous fungal growth has not received the same attention as bacterial growth modelling. This may be due to the inherent complexity of fungal growth quantification (Gibson and Hocking, 1997).

The study of the combined effects of temperature and $a_{\mathrm{w}}$ can contribute to understanding the population dynamics of $P$. expansum and the initiation of apple and pear fruit infection by this fungus. The main objectives of the present study were to determine 'in vitro' the influence of solutes, $a_{\mathrm{w}}$, temperature and their interactions on the growth rate of $P$. expansum and to construct models of its growth in relation to $a_{\mathrm{w}}$ and temperature.

\section{Materials and methods}

\subsection{Microorganism}

P. expansum (strain vs2) was isolated from decayed apple fruits (Unité de Phytopathologie, FUSAGx, Belgium). The strain was placed in tubes containing Potato Dextrose Agar (PDA; Merck KGaA 64271 Darmstadt, Germany) medium and covered with $10 \mathrm{ml}$ paraffin oil for long-term storage. In experiments, the initial inoculum was taken from cultures on PDA medium in Petri dishes preserved at $4{ }^{\circ} \mathrm{C}$ for no more than 6 months.

\subsection{Medium}

The basic medium used was PDA with an $a_{\mathrm{w}}$ of 0.995 . The $a_{\mathrm{w}}$ was modified by addition of increasing amounts of glycerol, sorbitol, glucose or $\mathrm{NaCl}$ (Teixidõ et al., 1998a) to obtain $a_{\mathrm{w}}$ levels of 0.980 , $0.960,0.930,0.910$ and 0.890 at 25,15 and $5{ }^{\circ} \mathrm{C}$. The $a_{\mathrm{w}}$ of all media was measured with an AquaLab series 3 instrument (Decagon, 950 NE Nelson Court Pullman, Washington 99163).

\subsection{Preparation of the mycelium inoculum}

A 10-day-old colony culture of $P$. expansum grown on PDA was used to obtain spore suspensions in sterile distilled water containing $0.05 \%$ Tween 80 . Spore suspensions were adjusted to $1 \times 10^{7}$ spores $/ \mathrm{ml}$ using a Bürker cell. Aliquots $(0.5 \mathrm{ml})$ of this suspension were spread over Petri dishes containing PDA medium. The Petri dishes were maintained at 25 ${ }^{\circ} \mathrm{C}$ for $24 \mathrm{~h}$ to obtain a mycelial layer. The myceliumbearing PDA was cut with a cork borer into discs $(0.5$ $\mathrm{cm}$ in diameter). Each disc was transferred to the centre of a plate containing a test medium. After inoculation, the Petri plates were sealed in polyethylene bags to prevent water loss and incubated at 5 , 15 or $25{ }^{\circ} \mathrm{C}$ for a maximum of 25 days. The preservation of water content in media was checked by $a_{\mathrm{w}}$ measurement of inoculated Petri dishes after 25 days at each temperature. The radius of each growing mycelial colony was measured daily in two directions at right angles to each other (Marin et al., 1996) without opening the Petri dishes. Three replicates were used per solute $-a_{\mathrm{w}}-$ temperature combination.

The radial growth rate $\left(\mathrm{mm} \mathrm{day}^{-1}\right)$ for each $a_{\mathrm{w}}$, solute and temperature combination was obtained from linear regression slopes of the temporal growth curves.

\subsection{Statistical analysis}

Growth rates were subjected to the general linear model (GLM) procedure of the Statistical Analysis System (SAS Institute, Cary, NC). Statistical significance was judged at the $P<0.05$ level. When analysis 
revealed statistically significant differences, Duncan's multiple range test for separation of means was performed.

\subsection{Experimental design}

Response surface methodology (RSM) with a $3^{k}$ factorial design was applied with the STATGRAPHICS Plus version 3 statistical software. Temperature $(25,15$ and $\left.5{ }^{\circ} \mathrm{C}\right)$ and $a_{\mathrm{w}}(0.980,0.930$ and 0.890$)$ were investigated (Table 2). Data modelling was done by multiple regression analysis. The design contains 9 experiments with three replicates. The response surface was obtained for growth rate. A second-order polynomial model was defined to fit the response:

$Y=\beta_{0}+\sum_{i=1}^{2} \beta_{i} X_{i}+\sum_{i=1}^{2} \beta_{i i} X_{i}^{2}+\sum_{i=1}^{2} \sum_{J=i+1} \beta_{i j} X_{i} X_{j}$

where $Y$ is the response (growth rate), $\beta_{0}$ is a constant coefficient, $X_{i}$ are coded variables ranging from -1 to $+1, \beta_{i}$ represent linear coefficients, $\beta_{i j}$ are the secondorder interaction coefficients, and $\beta_{i i}$ are the quadratic coefficients. All values of model coefficients were calculated by multiple regression analysis. Interpretation of the data was based on the signs (positive or negative effect on the response) and statistical signifi-
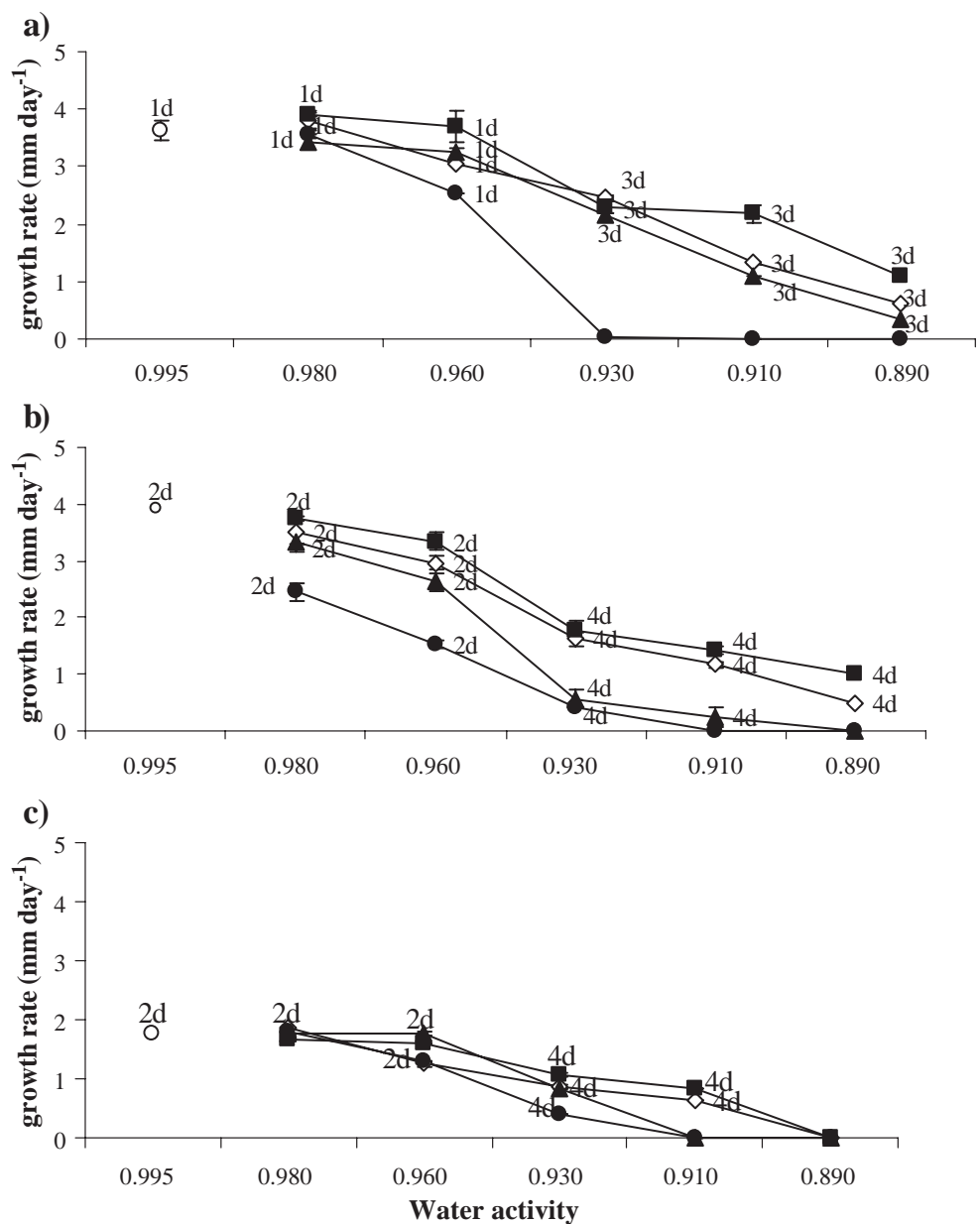

Fig. 1. Effect of water activity on growth rate of P. expansum in modified medium with, glycerol $(\mathbf{\square})$, sorbitol $(\diamond)$, glucose $(\boldsymbol{\Delta})$ and $\mathrm{NaCl}(\boldsymbol{\bullet})$ and unmodified medium $0.995(\mathrm{O})$ at $25^{\circ} \mathrm{C}(\mathrm{a}), 15^{\circ} \mathrm{C}(\mathrm{b})$ and $5{ }^{\circ} \mathrm{C}(\mathrm{c})$. The number of days for initiation of growth is shown. Bars represent the standard error of the means. Where the bars are not shown, they are smaller than the symbol size. 
cance of coefficients $(P<0.05)$. Interactions between two factors could appear as an antagonistic effect (negative coefficient) or a synergistic effect (positive coefficient). Comparisons between models were based on coefficient $R^{2}$ values.

\section{Results}

\subsection{Effects of solute, water activity and temperature on growth rate}

Fig. 1a shows the growth rate $\left(\mathrm{mm}\right.$ day $\left.^{-1}\right)$ of $P$. expansum at $25{ }^{\circ} \mathrm{C}$ on PDA medium supplemented with various solutes used to adjust the $a_{\mathrm{w}}$. In general, the growth rate decreased as the $a_{\mathrm{w}}$ of the medium decreased. The growth rate was highest at $a_{\mathrm{w}}=0.980$ whatever the solute. In the presence of added sorbitol, glucose or glycerol, $P$. expansum was able to grow at $a_{\mathrm{w}}$ values down to 0.890 . In the presence of added $\mathrm{NaCl}$, growth stopped at $a_{\mathrm{w}}=0.930$.

At $15{ }^{\circ} \mathrm{C}$, initiation of colony growth required an additional day as compared to initiation at $25{ }^{\circ} \mathrm{C}$. Despite this, the growth rate was only slightly lower at $15{ }^{\circ} \mathrm{C}$ than at $25{ }^{\circ} \mathrm{C}$ (Fig. 1b). At $a_{\mathrm{w}}=0.980$, the growth rate was highest on PDA supplemented with glucose, sorbitol or glycerol. Growth again slowed down as the $a_{\mathrm{w}}$ decreased. It stopped at $0.910 a_{\mathrm{w}}$ in

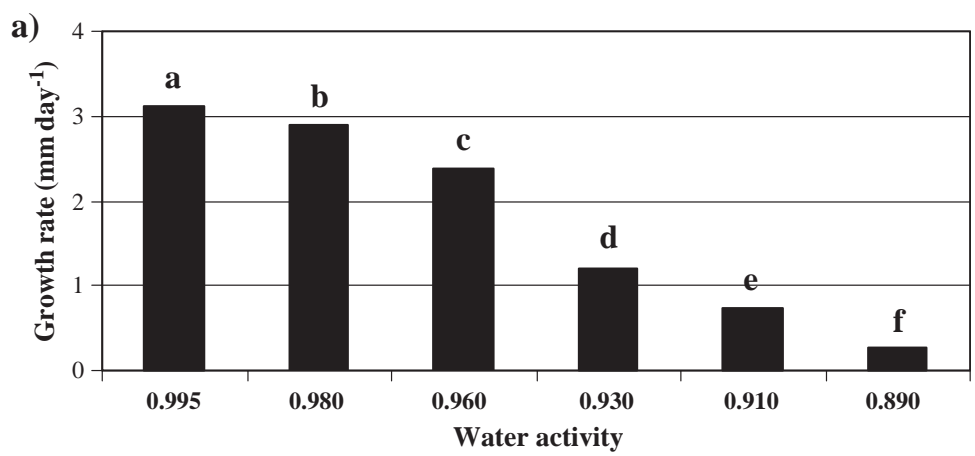

b)

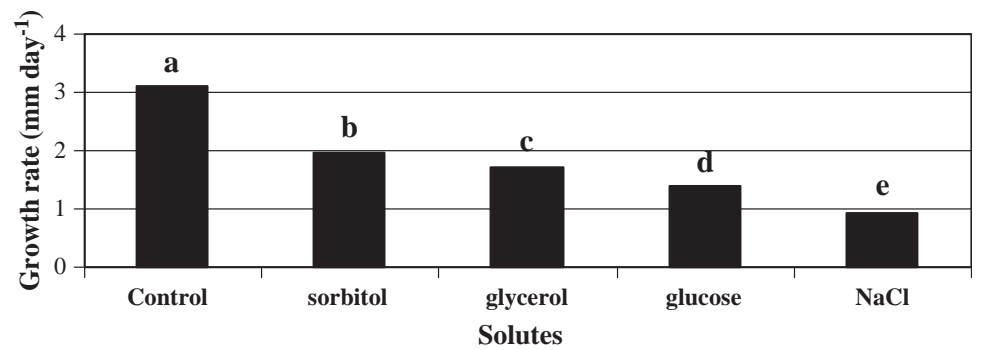

c)

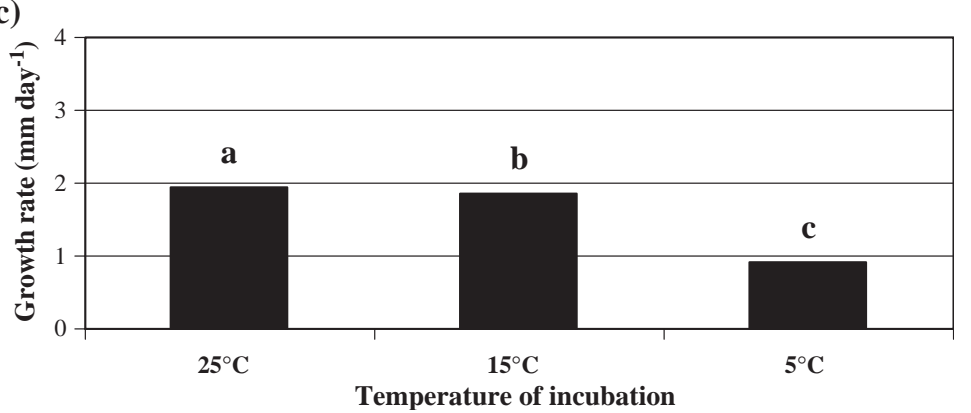

Fig. 2. Comparison of $P$. expansum growth rate averages per treatment [water activity (a), solutes (b) and temperature of incubation (c)] performed by the Duncan's range multiple test. The treatments having same letters are not significantly different $(P<0.05)$. 
Table 1

Variance analysis of effect of water activity $\left(a_{\mathrm{w}}\right)$, temperature $(t)$ and solute (sol) (two- and three-way interactions) on the growth rate of $P$. expansum in non-modified and modified PDA medium

\begin{tabular}{lrrrl}
\hline Source & $d f$ & \multicolumn{1}{c}{ MS } & \multicolumn{1}{c}{$F$} & $\operatorname{Pr}>F$ \\
\hline Sol & 3 & 8.9300861 & 425.31 & $0.0001^{* *}$ \\
$a_{\mathrm{w}}$ & 4 & 43.8653443 & 2089.14 & $0.0001^{* *}$ \\
$t$ & 2 & 20.8250452 & 991.82 & $0.0001^{* *}$ \\
Sol $\times a_{\mathrm{w}}$ & 12 & 0.4852583 & 23.11 & $0.0001^{* *}$ \\
Sol $\times t$ & 6 & 2.1855280 & 104.09 & $0.0001^{* *}$ \\
$a_{\mathrm{w}} \times t$ & 8 & 1.3828046 & 65.86 & $0.0001^{* *}$ \\
Sol $\times a_{\mathrm{w}} \times t$ & 24 & 0.2651708 & 12.63 & $0.0001^{* *}$ \\
\hline
\end{tabular}

$\mathrm{MS}$, mean square.

** Significant $(P<0.0001)$.

the presence of added $\mathrm{NaCl}$ and at 0.890 in the presence of added glucose. On PDA supplemented with sorbitol or glycerol, $P$. expansum was able to grow at all $a_{\mathrm{w}}$ values tested.

At $5{ }^{\circ} \mathrm{C}$, growth stopped at $0.890 a_{\mathrm{w}}$ (glycerol, sorbitol) or $0.910(\mathrm{NaCl}$, glucose) (Fig. 1c). Growth rates were much lower than at $25{ }^{\circ} \mathrm{C}$ and $15{ }^{\circ} \mathrm{C}$, being approximately halved as compared to growth at these temperatures at the same $a_{\mathrm{w}}$ in the presence of the same solute. Initiation of colony growth again occurred 1 day later at $5{ }^{\circ} \mathrm{C}$ than at $25^{\circ} \mathrm{C}$.

Statistical analysis of the data, based on variance analysis with three criteria, provided evidence of highly significant effects $(P<0.0001)$ of $a_{\mathrm{w}}$, solutes, incubation temperature and interactions thereof on the growth rate of $P$. expansum (Table 1). Duncan's multiple range analysis confirmed a significantly higher growth rate at 0.995 (control) and $0.980 a_{\mathrm{w}}$, than under any other conditions tested, whatever the solute used to adjust the $a_{\mathrm{w}}$ of medium (Fig. 2a). Concerning the incubation temperature, a similar test revealed three statistically homogenous groups, one for each temperature (Fig. 2c). Growth was fastest at $25{ }^{\circ} \mathrm{C}: 1.95 \mathrm{~mm} \mathrm{day}{ }^{-1}$ as compared to $1.86 \mathrm{~mm}$ day ${ }^{-1}$ at $15{ }^{\circ} \mathrm{C}$ and $0.92 \mathrm{~mm}$ day ${ }^{-1}$ at $5{ }^{\circ} \mathrm{C}$. Finally, the test revealed five distinct groups for the influence of solutes (Fig. 2b). The growth rate was highest on the unmodified medium $\left(3.11 \mathrm{~mm} \mathrm{day}^{-1}\right)$, reduced in the presence of added sorbitol $\left(1.95 \mathrm{~mm} \mathrm{day}^{-1}\right)$ or glycerol $\left(1.70 \mathrm{~mm} \mathrm{day}^{-1}\right)$, and reduced more strongly when $\mathrm{NaCl}\left(0.93 \mathrm{~mm} \mathrm{day}^{-1}\right)$ or glucose $(1.40 \mathrm{~mm}$ day $^{-1}$ ) was added.

\subsection{Modelling the growth rate of $P$. expansum}

The modelling data used were those concerning the solutes glycerol and sorbitol, whose effect on the growth rate of $P$. expansum appeared to be lesser than that of $\mathrm{NaCl}$ and glucose.

The average growth rates obtained with the model under the various conditions are reported in Table 2. Except for $a_{\mathrm{w}}=0.890$ at $15{ }^{\circ} \mathrm{C}$, no great difference was observed between the observed values and those predicted by the sorbitol model. This model predicts slight growth at $a_{\mathrm{w}}=0.890$ at $5{ }^{\circ} \mathrm{C}$, while the glycerol model does not. The glycerol model, in

Table 2

Experimental and predicted values of growth rate of $P$. expansum obtained by applying factorial design $\left(3^{k}\right)$ methodology for temperature and $a_{\mathrm{w}}$ with glycerol and sorbitol models

\begin{tabular}{|c|c|c|c|c|c|c|c|c|}
\hline \multirow[t]{3}{*}{ Experiment } & \multicolumn{4}{|c|}{ Environmental factors } & \multicolumn{4}{|c|}{ Extension growth rate } \\
\hline & \multicolumn{2}{|c|}{ Experimental values } & \multicolumn{2}{|l|}{ Coded values } & \multicolumn{2}{|c|}{ Glycerol model } & \multicolumn{2}{|c|}{ Sorbitol model } \\
\hline & Temperatures & $a_{\mathrm{w}}$ & Temperatures & $a_{\mathrm{w}}$ & Observed & Predicted & Observed & Predicted \\
\hline E1 & 5 & 0.890 & -1 & -1 & $0.00 \pm 0.00$ & 0.00 & $0.00 \pm 0.00$ & 0.08 \\
\hline E2 & 15 & 0.890 & 0 & -1 & $0.45 \pm 0.08$ & 0.57 & $1.00 \pm 0.16$ & 1.06 \\
\hline E3 & 25 & 0.890 & +1 & -1 & $0.61 \pm 0.05$ & 0.50 & $1.08 \pm 0.07$ & 0.94 \\
\hline E4 & 5 & 0.930 & -1 & 0 & $0.87 \pm 0.02$ & 0.88 & $1.07 \pm 0.01$ & 0.80 \\
\hline E5 & 15 & 0.930 & 0 & 0 & $1.60 \pm 0.06$ & 1.89 & $1.78 \pm 0.28$ & 2.08 \\
\hline E6 & 25 & 0.930 & +1 & 0 & $2.47 \pm 0.13$ & 2.21 & $2.28 \pm 0.15$ & 2.26 \\
\hline E7 & 5 & 0.980 & -1 & +1 & $1.85 \pm 0.01$ & 1.89 & $1.67 \pm 0.03$ & 1.89 \\
\hline E8 & 15 & 0.980 & 0 & +1 & $3.43 \pm 0.25$ & 3.28 & $3.76 \pm 0.05$ & 3.47 \\
\hline E9 & 25 & 0.980 & +1 & +1 & $3.80 \pm 0.10$ & 3.99 & $3.89 \pm 0.05$ & 3.95 \\
\hline
\end{tabular}

The coded values $\left(X_{i}\right)$ were calculated from experimental values $\left(U_{i}\right)$ using formula: $\left.X_{i}=\left\{2 U_{i}-\left(U_{\max }+U_{\min }\right)\right\} /\left(U_{\max }-U_{\min }\right)\right\}$ where $X_{i}$ is the coded value ranged between $-1\left(U_{\min }\right)$ and $+1\left(U_{\max }\right)$, and $U_{i}$ the experimental values. The intermediate values for temperature and $a_{\mathrm{w}}$ were calculated using this formula. 
contrast, generally yielded values higher than the observed values.

To determine the conditions for growth of $P$. expansum, response surfaces showing the predicted effects of $a_{\mathrm{w}}$ and temperature were drawn from both established equation models (Fig. 3). For both models, the response surface showed a growth rate very sensitive to the $a_{\mathrm{w}}$ of the medium and to the incubation temperature. Growth was predicted to be faster at an $a_{\mathrm{w}}$ ranging from 0.960 to 0.980 , whatever the temperature tested. The highest growth rate was observed at $25{ }^{\circ} \mathrm{C}$.

The results of multiple regression analysis, which provided the estimates of the model coefficients, are listed in Table 3. Coefficient $R^{2}$ values were equal to 97.95 and 97.00 for the glycerol and sorbitol models, respectively. In both models, all coefficients were highly significant $(P<0.0001)$, except for coefficient $\beta_{22}$ (quadratic effect of $a_{\mathrm{w}}$ ). For $\beta_{22}$, the $P$ values were 0.67 and 0.07 for the glycerol and sorbitol model, respectively. The higher the absolute value of a linear coefficient $\left(\beta_{1}\right.$ or $\left.\beta_{2}\right)$, the greater the influence of the corresponding factor (temperature or $a_{\mathrm{w}}$ ) on the growth rate. Thus, in all cases, the influence of $a_{\mathrm{w}}$ was
Table 3

Model coefficients and their significant effects on $P$. expansum growth rate obtained for both solutes glycerol and sorbitol

\begin{tabular}{llclc}
\hline$R^{2}$ & Coefficients & Glycerol & & Sorbitol \\
\cline { 5 - 5 } & & 97.95 & & 97.00 \\
\hline Response means & $\beta_{0}$ & $1.90^{* * *}$ & & $2.08^{* * *}$ \\
$t$ & $\beta_{1}$ & $0.66^{* * *}$ & & $0.73^{* * *}$ \\
$a_{\mathrm{w}}$ & $\beta_{2}$ & $1.35^{* * *}$ & & $1.20^{* * *}$ \\
$t^{2}$ & $\beta_{11}$ & $-0.34^{* * *}$ & & $-0.55^{* * *}$ \\
$a_{\mathrm{w}}^{2}$ & $\beta_{22}$ & $0.03^{\text {ns }}$ & & $0.18^{\text {ns }}$ \\
$t \times a_{\mathrm{w}}$ & $\beta_{12}$ & $0.38^{* * *}$ & $0.30^{* * *}$ \\
\hline
\end{tabular}

ns=not significant.

*** Significant $(P<0.0001)$.

greater than that of temperature. In both models, $a_{\mathrm{w}}$ and temperature had a positive linear effect on the growth rate of $P$. expansum. Whatever the constructed models, temperature and $a_{\mathrm{w}}$ had respectively a negative quadratic effect and positive quadratic effect.

\section{Discussion}

In this work, we have modelled, for the first time, the growth rate of $P$. expansum according to temper-
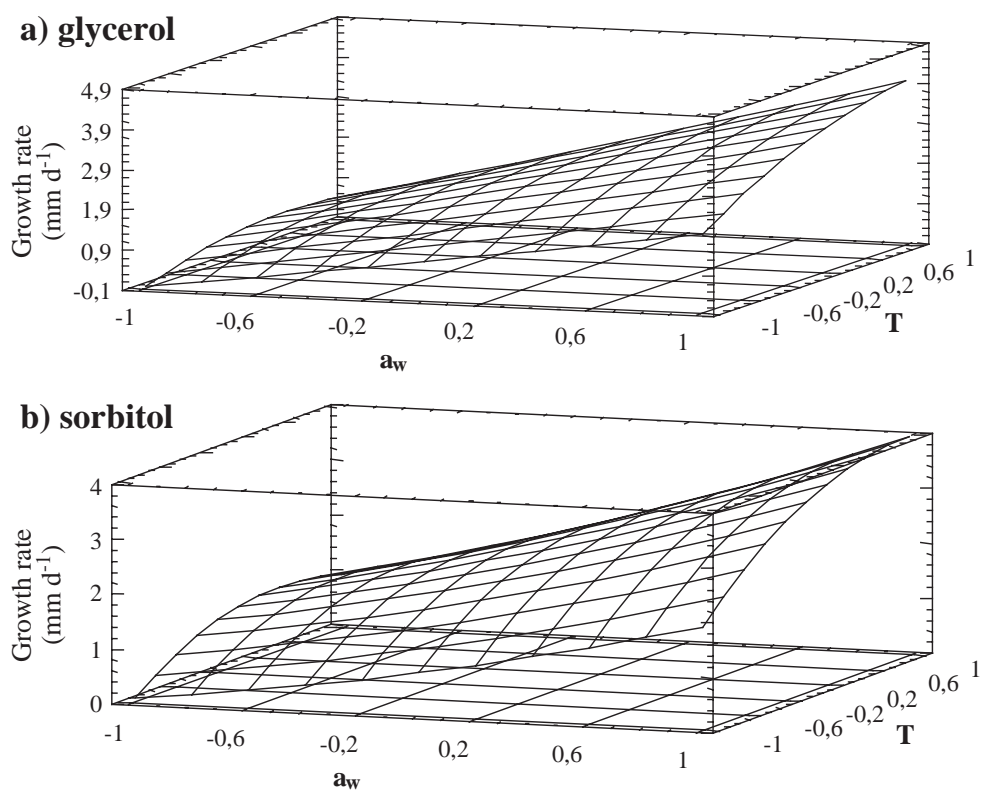

Fig. 3. Response surface representing the predicted effect of water activity $\left(a_{\mathrm{w}}\right)$ and temperature $(T)$ by both models glycerol (a) and sorbitol (b) on growth rate of $P$. expansum. Coded values -1 and +1 represent, respectively, the minimal and the maximal limits of the values of both factors temperatures and water activity. 
ature and $a_{\mathrm{w}}$, two major factors affecting fungal growth. The aim was to understand the population dynamics of this pathogenic fungus in order to develop more rational strategies of disease control.

The results show that, on PDA medium supplemented or not with various solutes used to alter the water activity of the medium, $P$. expansum grows best at temperatures from 15 to $25^{\circ} \mathrm{C}$ and at an $a_{\mathrm{w}}$ ranging from 0.960 to 0.980 . At low temperature $\left(5{ }^{\circ} \mathrm{C}\right), P$. expansum can grow at a low $a_{\mathrm{w}}(0.890)$, depending on the solute used to reach this $a_{\mathrm{w}}$. Similar studies have been carried out on other Penicillium species. Plaza et al. (2003) report that $P$. italicum can germinate and grow at $a_{\mathrm{w}}=0.870,25^{\circ} \mathrm{C}$. Gock et al. (2003) have shown that $P$. roqueforti can germinate at $a_{\mathrm{w}}=0.820$, $25{ }^{\circ} \mathrm{C}$. Growth of $P$. chrysogenum was minimal at 25 ${ }^{\circ} \mathrm{C}$ at $a_{\mathrm{w}}$ values ranging from 0.780 to 0.810 (Hocking and Pitt, 1979; Sautour et al., 2001a).

The choice of solute used to modify the water activity of a medium has a significant impact on the growth rate of the yeast Candida sake (Teixidõ et al., 1998a,b). Our study likewise shows that sorbitol and glycerol have a lesser effect on the growth rate of $P$. expansum than $\mathrm{NaCl}$ and glucose.

The need to ensure the microbiological safety and quality of food products has stimulated interest in the use of mathematical models for quantifying and predicting microbial behaviour. Most predictive models have been developed for pathogenic bacteria. The main problem has been the difficulty of acquiring sufficient reproducible data, suitable for modelling (Buchanan, 1993; Gibson and Hocking, 1997). Here we have modelled the combined effects of temperature and $a_{\mathrm{w}}$ on the $P$. expansum growth rate. The data obtained with both sorbitol and glycerol were modelled by means of the quadratic polynomial model. The difference between the two models was slight, except at $a_{\mathrm{w}}=0.890$ where $P$. expansum shows slower growth in the sorbitol model. This difference may be due to the error on our $a_{\mathrm{w}}$ estimates on PDA medium or to the variability of our experimental results. $R^{2}$ values show that $a_{\mathrm{w}}$ and temperature account for $98 \%$ of the growth-rate variation observed in the glycerol model and $97 \%$ of that observed in the sorbitol model (Box and Draper, 1987). Similar models have been established for other food spoilage pathogens such as Rhizopus oligosporus NRRL 2710 (Sparringa et al., 2002) and P. chrysogenum (Sautour et al., 2001a,b; El-Halouat and Debevere, 1997). The results of our study are in accordance with those of Sautour et al. (2001a), who report no significant difference between a glycerol and a sorbitol model based on germination of $P$. chrysogenum and show that $a_{\mathrm{w}}$ has a greater effect on germination than temperature.

Both models established here provide better understanding of the development of apple decay caused by $P$. expansum. They give a better idea of the epidemiology and behaviour of this pathogen with respect to temperature and $a_{\mathrm{w}}$ within the ranges studied here. Yet extrapolation of these models to natural situations is hazardous, because other factors such as $\mathrm{pH}$, nutrient availability and interactions with other microorganisms at the surface of the fruit could change the behaviour of this pathogen. For this reason, further studies are needed to develop experimental protocols for evaluating the effect of $a_{\mathrm{w}}$ and temperature on the $P$. expansum growth rate on the fruit surface and to validate both models 'in vivo'. Implementation of these results should contribute to elaborating a more rational control strategy against blue mould on apple and pear fruits.

\section{Acknowledgements}

The authors wish to express their gratitude to the AUF (Agence Universitaire de la Francophonie) for its financial contribution to this paper.

\section{References}

Bondoux, P., 1992. Maladies de conservation des fruits à pépins: pommes et poires. INRA, Paris, France. 173 pp.

Box, G.E.P., Draper, N.R., 1987. Least squares for response surface work. Empirical Model Building and Response Surfaces. John Wiley, New York, pp. 34-103.

Buchanan, L.R., 1993. Predictive food microbiology. Trends in Food Science \& Technology 4, 6-11.

El-Halouat, A., Debevere, J.M., 1997. Effect of water activity, modified atmosphere packaging and storage temperature on spore germination of moulds isolated from prunes. International Journal of Food Microbiology 35, 41-48.

Gervais, P., Berlin, J.M., Sarrette, M., 1988a. Influence of water activity on aroma production by Trichoderma viride growing on solid substrate. Journal of Fermentation Technology 66, 403-407. 
Gervais, P., Grajek, W., Bensoussan, M., Molin, P., 1988b. Influence of water activity of a solid substrate on the growth rate and sporogenesis of filamentous fungi. Biotechnology and Bioengineering 31, 457-463.

Gibson, A.M., Hocking, A.D., 1997. Advances in the predictive modelling of fungal growth in food. Trends in Food Science \& Technology 8, 353-358.

Gock, M.A., Hocking, A.D., Pitt, J., Poulos, P., 2003. Influence of temperature, water activity and $\mathrm{pH}$ on growth of some xerophilic fungi. International Journal of Food Microbiology $81,11-19$.

Hocking, A.D., Pitt, J.I., 1979. Water relations of some Penicillium species at $25 \operatorname{deg}$ C. Transactions of the British Mycological Society $73,141-145$.

Lacey, J., 1989. Pre- and post-harvest ecology of fungi causing spoilage of foods and other stored products. Journal of Applied Bacteriology Symposium Supplement 67, 11S-25S.

Loussert, R., 1985. Les agrumes, vol. 1. Lavoisier, Paris, p. 113.

Magan, N., Lacey, J., 1988. Ecological determinants of mould growth in stored grain. International Journal of Food Microbiology 7, 245-256.

Marin, S., Sanchis, V., Teixidõ, A., Saenz, R., Ramos, A.J., Vinãs, I., Magan, N., 1996. Water and temperature relations and microconidial germination of Fusarium moniliforme and $F$. proliferatum from maize. Canadian Journal of Microbiology 42, $1045-1050$.

McMeekin, T.A., Olley, J.N., Ross, T., Ratkowsky, D.A., 1993. Predictive Microbiology: Theory and Application. Research Studies Press, Taunton, UK.

McMeekin, T.A., Olley, J.N., Ratkowsky, D.A., Ross, T., 2002. Predictive microbiology: towards the interface and beyond. International Journal of Food Microbiology 73, 395-407.

Plaza, P., Usall, J., Teixidõ, N., Vinãs, I., 2003. Effect of water activity and temperature on germination and growth of Penicillium digitatum, P. italicum and Geotrichum candidum. Journal of Applied Microbiology 94, 549-554.

Rosenberger, D.A., 1990. Compendium of Apple and Pear Diseases. APPS Press, Minnesota, USA, pp. 53-55.

Sautour, M., Rouget, A., Dantigny, P., Divies, C., Bensoussan, M., 2001a. Prediction of conidial germination of Penicillium chrysogenum as influenced by temperature, water activity and pH. Letters in Applied Microbiology 32, 131-134.

Sautour, M., Rouget, A., Dantigny, P., Divies, C., Bensoussan, M., 2001b. Application of Dohlert design to determinate the combined effects of temperature, water activity and $\mathrm{pH}$ on conidial germination of Penicillium chrysogenum. Journal of Applied Microbiology 91, 1-7.

Sparringa, R.A., Kendall, M., Westby, A., Owens, J.D., 2002. Effects of temperature, $\mathrm{pH}$, water activity and $\mathrm{CO}_{2}$ concentration on growth of Rhizopus oligospous NRRL 2710. Journal of Applied Microbiology 92, 329-337.

Teixidõ, N., Vinãs, I., Usall, J., Sanchis, V., Magan, N., 1998a. Ecophysiological responses of the biocontrol yeast of Candida sake to water, temperature and stress. Journal of Applied Microbiology 84, 192-200.

Teixidõ, N., Vinãs, I., Usall, J., Magan, N., 1998b. Improving ecological fitness and environmental stress tolerance of the biocontrol yeast Candida sake by manipulation of intracellular sugar alcohol and sugar content. Mycological Research 102 (11), 1409-1417. 